\title{
MICROMACHINE FOR LOCOMOTION INSIDE PIPE
}

The paper deals with miniature machine for locomotion inside pipe. It uses impact energy as a principle of motion. Dynamics description and simulation model has been created. The deviations of the features are resulting from the fact that within the simulation model the friction between the bristle and the pipe wall is presented through the model not regarding the variability of the friction force and existing geometric deviations of the pipe inner surface.

Keywords: mobile machine, pipelines, simulation

\section{Introduction}

There are many applications where it is necessary to make inspection of pipes like steam generators, power plants, heat exchangers, chemical plants etc. Very often, the inspection is possible to be made only from the internal side of pipes. In-pipe machines are developed for this purpose. Inspection made via using of these in-pipe machines is needed as a prevention tool before dangerous accidents. This requirement was a driving impulse for the research and developing of in-pipe machines. The in-pipe machine is able to locomote inside the pipe and makes any activities like carrying of inspection tools or making repairmen of pipes [1-20].

The topic of this paper is in-pipe machine, which is designed for locomotion inside the pipe with inner diameter $11 \mathrm{~mm}$ (Figure $1)$.

\section{Description of locomotion principle}

For in-pipe locomotion the micromachine (Figure 1) uses the energy released during the impact of the two bodies [16-17] where one of the bodies is the drive (permanent magnet) and another one is driven (other parts of the micromachine). The driven body consists of the electromagnet and the guiding rod and the adjusting module. The drive body-permanent magnet (SmCo - Samarium Cobalt) is of a cylindrical shape with the axial hole and moves under the influence of the magnetic force and on the guiding rod between two impact surfaces of the driven body.
The active surface is one of the impact surfaces of the driven body (Figure 1). The second of the impact surfaces consists of the abutting surface of the helical spring being the part of the adjusting module. The front electromagnet position of the spring may be adjusted by the adjusting module.

The inertial stepping principle (Figure 2) rises from the impact of the drive body (permanent magnet) on the micromachine driven body.

On the perimeter of both the adjusting module and the electromagnet cover there are fixed the bristles. The bristles provide the micromachine contact with the inner pipe wall. The micromachine one-way locomotion results from the fact that the impact force on the active surface exceeds the frictional force between the bristles and the inner pipe wall and it does not apply for the impact force on the adjusting module spring. The micromachine diameter is $11 \mathrm{~mm}$ and its length is $35 \mathrm{~mm}$.

The drive body-permanent magnet is embedded on a brass sleeve (Figure 1) with which it is moving on the guiding rod. The solenoid coil is excited by the square current pulses. A stabilized current supply maintains the constant value of the current pulse. Both the width and the frequency of the pulses may be adjusted by the single board microcomputer.

So that to take into account the essential details influencing the micromachine locomotion is an advisable micromachine operation to be divided into three tacts interlocking one another:

1. preparing tact,

2. active tact,

3. regeneration tact.

These tacts together form the micromachine motion cycle repeating during its operation with the repetitive frequency $f$ resp.

\footnotetext{
* Lubica Mikova, Ivan Virgala, Michal Kelemen, Tomas Liptak, Darina Hroncova

Department of Mechatronics, Faculty of Mechanical Engineering, Technical University of Kosice, Slovakia

E-mail: michal.kelemen@tuke.sk
} 

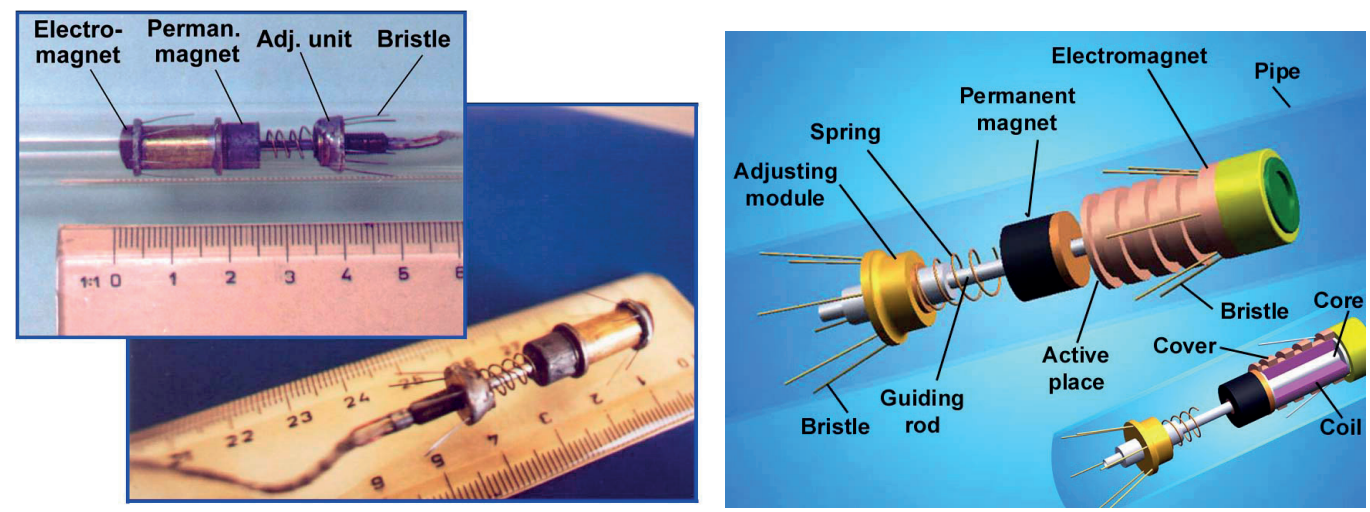

Figure 1 Overall micromachine arrangement

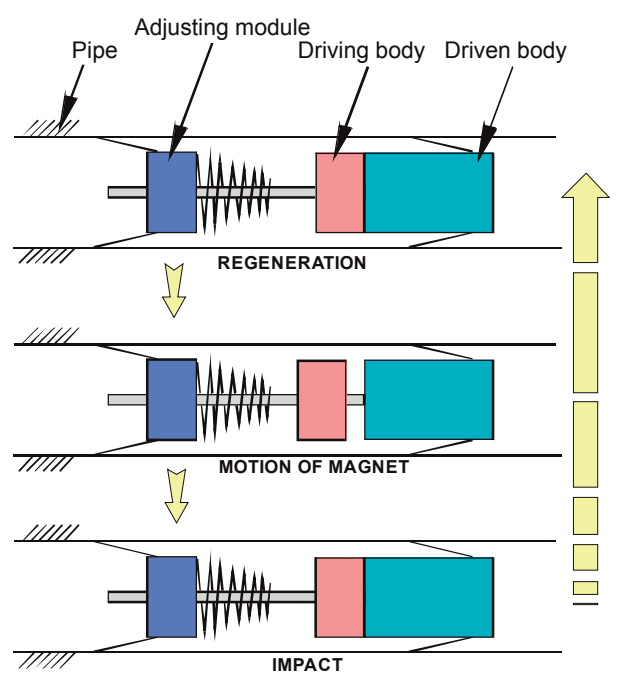

Figure 2 Simplified locomotion principle

with the time of the cycle $T$. The respective tacts are divided into the phases. The diagram of the time decomposition and the initial and final phases times are shown in Figure 3. Further, there is described the operation of the micromachine during the respective phases and based on the micromachine model according to Figure 4.

The preparing tact consists of three phases: A, B, C (Figure 3 and Figure 5). During the initial part of the phase $\mathbf{A}$ the drive body (permanent magnet) contacts the active surface of the micromachine as the result of affecting attractive force $F_{p}$ (Figure $4)$. Through the current impulse supplying into the coil of the electromagnet in the time $t=t_{A}$ the repulsive force $F_{O}$ is activated where $\left|F_{o}\right|>\left|F_{P}\right|$ and resulting in drive body (permanent magnet) motion towards the adjusting module. The frictional force between the magnet and the guiding rod $F_{l}$ counterworks the permanent magnet motion. The time of duration of the repulsive force is adjusted experimentally and for example according to demanded micromachine motion speed and following the distance of the adjusting model spring $x_{l P}$ from the micromachine permanent magnet. In the moment of finishing the repulsive force (time $t=t_{B}$ ) the phase A terminates and the phase B starts.

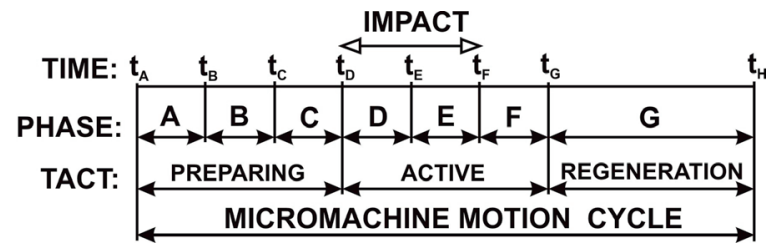

Figure 3 Time decomposition of micromachine motion cycle

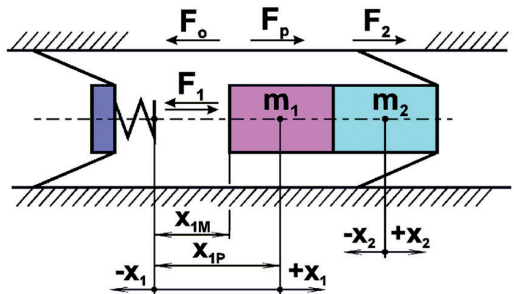

Figure 4 Simplified micromachine model ( $m_{1}$ driving body, $m_{2}$ driven body)

The phase B starts in the moment of termination of the repulsive force $F_{O}$ in the time of $t=t_{B}$ and is finishing in the moment of termination of the driving body contact with the adjusting module spring in the time of $t=t_{C}$. During this phase the driving body is affected by the attractive force $F$. The absolute value of the damping spring deformation force resulting from the driving body impact on the adjusting module spring is lower than the absolute value of the frictional force $F_{2}$ during this phase. It means that the in-pipe machine does not change its position. The theoretical analysis [16] results in the fact that the maximum speed of the driving body impact on the active surface of the in-pipe machine occurs at the time when the repulsive force $F_{o}$ works up to the moment of the maximum compression of the adjusting module spring.

The phase $\mathbf{C}$ starts at the moment of finishing the drive body and spring contacts during the phase $\mathrm{B}$ and in the time of $t=t_{\mathrm{C}}$. Within this phase the drive body is accelerated by the attractive force $F_{P}$ and towards the active impact surface of the in-pipe micromachine. At the moment of the contact with this surface and in the time of $t=t_{D}$ this phase is finished and the phase D of the active tact starts. 


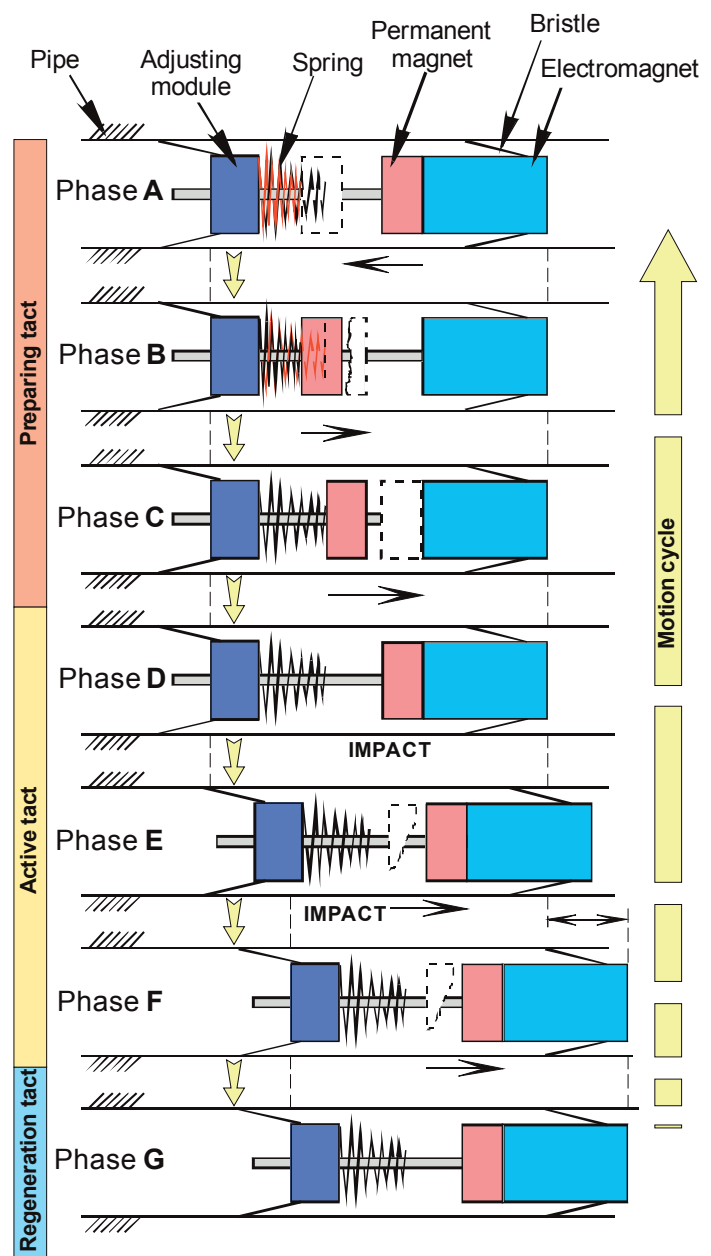

Figure 5 Micromachine motion cycle

The active tact consists of three phases: D, E, F (Figure 3 and Figure 5).

The phase $\mathbf{D}$ starts at the moment when the drive body contacts the driven body on the active impact surface. The phase $\mathrm{D}$ is an immediate continuation of the preparing tact and its duration is limited by duration of the impact of both the driven and drive bodies and in the time of $t=t_{D}$ and it finishes when the driving force $F_{h}$ is equal to the frictional force $F_{2}$ and in the time of $t=t_{E}$. It means that the in-pipe machine is motionless (it does not change its position).

The phase $\mathbf{E}$ starts at the moment of $t=t_{E}$, when the driving force is equal to the frictional force $F_{h}=F_{2}$ and it is finishing in the time of $t=t_{F}$, when the driving force is $F_{h}=0$. During the entire phase the in-pipe machine is in motion.

The phase $\mathbf{F}$ immediately follows the drive and driven bodies impact on the active surface and in the time of $t=t_{F}$ and it finishes at the moment when the micromachine stops and in the time of $t=t_{G}$ and when the micromachine activity turns to the regeneration tact.

The regeneration tact consists only of one phase $\mathbf{G}$ (Figure 3 and Figure 5). In the time of $t_{H}-t_{G}$ its duration is determined by allowed operational micromachine temperature (the heating up results from the joule loss in the coil of electromagnet). The coil is cooling down and both the in-pipe machine and the permanent magnet are motionless during this phase.

\section{Dynamics of the machine}

Regarding the preparation of the in-pipe machine description a simplified model is used (Figure 2 and Figure 5). The following description is prepared providing the motion within the horizontal pipe.

The beginning of the phase A falls within the time of the impact where the time in which the set mechanism initiates the repulsive force i.e. the speed of the driving body changes the positive speed sign to the negative speed of $\left(t=t_{A}\right)$. The repulsive force lasts up to the moment when the speed drops to zero due to the deformation force of the adjusting module spring. At this moment $\left(t=t_{B}\right)$ the phase A is finished and the phase B starts. The state space equations are responding to the phase $\mathrm{A}$ as follows:

a) Phase $\mathrm{A}$ with no adjusting module spring contact

$$
\begin{aligned}
& \frac{d x_{1}(t)}{d t}=v_{1}(t) \\
& \frac{d v_{1}(t)}{d t}=\frac{1}{m_{1}} \cdot\left[F_{o}\left(x_{1}\right)-F_{1}\left(v_{1}\right)\right]
\end{aligned}
$$

b) Phase $\mathrm{A}$ in adjusting module spring contact

$$
\begin{aligned}
& \frac{d x_{1}(t)}{d t}=v_{1}(t) \\
& \frac{d v_{1}}{d t}=\frac{1}{m_{1}} \cdot\left[F_{o}\left(x_{1}\right)-F_{1}\left(v_{1}\right)-k_{p} \cdot\left(x_{1}(t)-x_{2}(t)-x_{1 P}\right)\right]
\end{aligned}
$$

The phase B starts at the time of $t=t_{B}$ and finishes at the moment of termination of the adjusting module spring contact in the time of $t=t_{C}$. The attractive force $F_{p}$ influences the driving body during this phase. The state space equations describing this phase are as follows:

$$
\begin{aligned}
& \frac{d x_{1}(t)}{d t}=v_{1}(t) \\
& \frac{d v_{1}}{d t}=\frac{1}{m_{1}} \cdot\left[F_{p}\left(x_{1}\right)-F_{1}\left(v_{1}\right)-k_{p} \cdot\left(x_{1}(t)-x_{2}(t)-x_{1 P}\right)\right]
\end{aligned}
$$

The phase $\mathrm{C}$ starts in the time of $t=t_{C}$ and finishes at the moment of the contact with the active in-pipe machine impact surface in the time of $t=t_{D}$. The driving body is accelerated by the attractive force $F_{p}$ during this phase. This phase is represented by the state space Equations (4).

$$
\begin{aligned}
& \frac{d x_{1}(t)}{d t}=v_{1}(t) \\
& \frac{d v_{1}(t)}{d t}=\frac{1}{m_{1}} \cdot\left[F_{p}\left(x_{1}\right)-F_{1}\left(v_{1}\right)\right]
\end{aligned}
$$




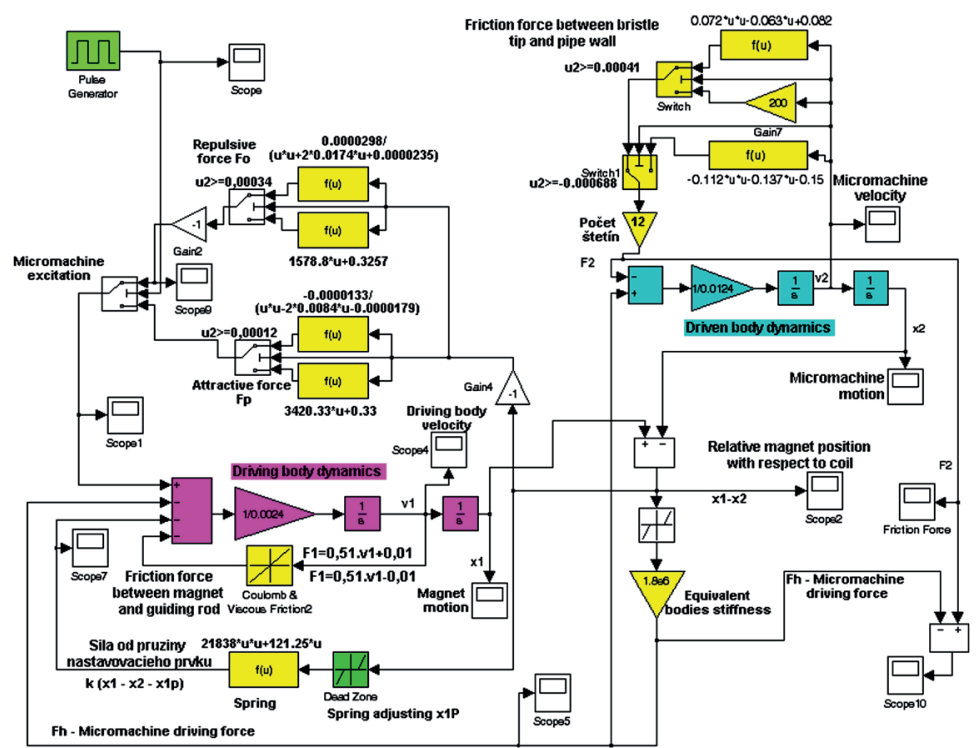

Figure 6 Simulation model of in-pipe machine

The phases D and $\mathrm{E}$ are connected since it may be described through the common scheme of the state space equations within the simulation experiment. The phase D starts at the moment of the driving and driven bodies contact on the active surface $(t=$ $\left.t_{D}\right)$. The phase $\mathrm{E}$ finishes at the moment of $t=t_{F}$ when the speed $v_{1}$ changes the positive sign for the negative value. The motion dynamics is described by the equation scheme as follows:

Phase $\mathrm{D}+$ phase $\mathrm{E}$ (time of impact with $v_{1} \geq 0$ )

$\frac{d x_{1}(t)}{d t}=v_{1}(t)$

$\frac{d v_{1}(t)}{d t}=\frac{1}{m_{1}} \cdot\left[F_{p}\left(x_{1}\right)-F_{1}\left(v_{1}\right)-F_{h}\right]$

$\frac{d x_{2}(t)}{d t}=v_{2}(t)$

$\frac{d v_{2}(t)}{d t}=\frac{1}{m_{2}} \cdot\left[F_{h}-F_{2}\left(v_{2}\right)\right]$

where $F_{h}=k_{e} \cdot\left[x_{1}(t)-x_{2}(t)\right]$

As in any moment the value of the attractive force is lower than the frictional force between the bristles and the pipe wall then no attractive force influencing the driven body motion will be regarded.

The phase $\mathrm{F}$ is immediately following the drive and driven bodies impact and it finishes at the time $t_{G}$ and at the moment of stopping the in-pipe machine. From the mathematical description aspect this phase is the most sophisticated. If the drive and driven bodies would not be influenced by the magnetic forces then the both bodies could move independently after the impact. As the mutual influence occurs then the entire course of this phase will be more complicated. In effort to avoid the complications it is predicted that the influence by the magnetic forces does not occurs and that the driven body is moving independently from the driving body. The state space equations of this phase are as follows:

$$
\begin{aligned}
& \frac{d x_{2}(t)}{d t}=v_{2}(t) \\
& \frac{d v_{2}(t)}{d t}=\frac{F_{2}\left(v_{2}\right)}{m_{2}}
\end{aligned}
$$

In the work [16] is derived the steady velocity of the micromachine:

$v_{2 s t r}=\frac{1}{T} \cdot \int_{t_{A}}^{t_{G}} v_{2}(t) d t=\frac{2 \cdot m_{r}^{2} \cdot v_{1 D d}^{2}}{m_{2} \cdot T \cdot F_{2}}, m_{r}=\frac{m_{1} \cdot m_{2}}{m_{1}+m_{2}}$

The steady velocity of the micromachine depends on the time of the micromachine cycle and on the integral of the micromachine driven body velocity.

\section{Simulation model of the machine and experimental results}

The simulation model which is shown in Figure 6, is assembled on the base of the previous description. The blocks, which are highlighted with yellow colour, represent the unknown parameters and dependencies:

- repulsive force between electromagnet and permanent magnet on relative distance between them,

- repulsive force between electromagnet and permanent magnet on relative distance between them,

- frictional force between the bristles and the pipe wall,

- friction force between the guiding rod and the magnet sleeve

These parameters and dependencies have been identified experimentally. 

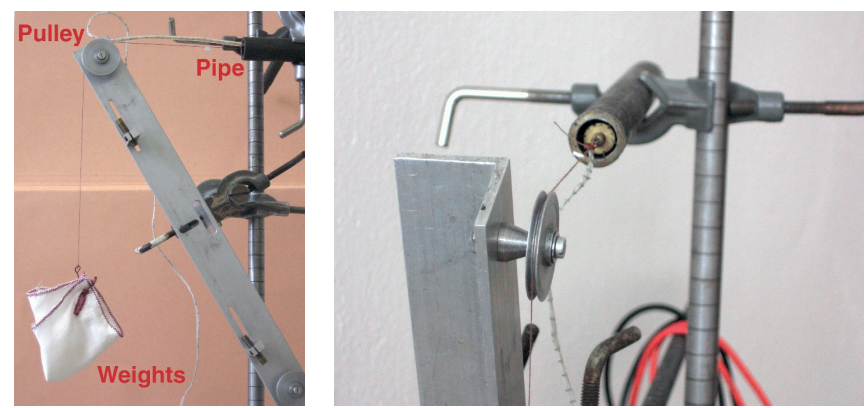

Figure 7 Experimental examination of the traction force and velocity of in-pipe machine locomotion in horizontal steel pipe

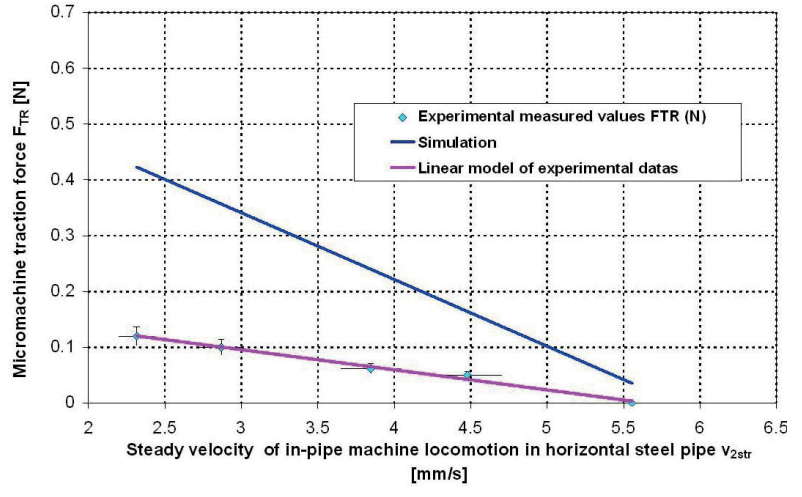

Figure 8 Traction force dependence on velocity of in-pipe machine locomotion in horizontal steel pipe

Blocks, which are highlighted with green colour, are input variables. Figure 6 shows the simulation model of the micromachine locomotion. The model consists of two basic subsystems, i.e. a dynamic of the driving body (highlighted with magenta colour in Figure 6) and the dynamic of the driven body (highlighted with cyan colour in Figure 6).

Based on the mentioned equations (1-6) the simulation model was prepared within Matlab/Simulink and where the unknown parameters and the relations were completed (Figure 6). Regarding the verification of the results there were realized the experiments concerning the in-pipe machine in the horizontal pipe (Figure 7).

Figure 8 shows the relation of the traction force to the velocity of in-pipe machine locomotion in horizontal pipe and determined by both the experiments and the simulations.

The deviations of the features are resulting from the fact that within the simulation model the friction between the bristle and the pipe wall is presented through the model not regarding the variability of the friction force and existing geometric deviations of the pipe inner surface. In full the geometric deviations of the pipe inner surface effect the changes of the reference bristle force on the pipe wall and the same the friction force between the pipe wall and the in-pipe machine tips of the bristle.

The mathematical model of the friction force was experimentally identified by a simplified model not regarding the geometric deviations of the pipe inner surface (dimension deviation, shape deviation, surface roughness) [16].

\section{Conclusion}

The paper describes the in-pipe machine based on the two bodies impact principle and which is from the category of the in-pipe machines utilizing the inertial stepping principle.

One of the most important problems occurring during the in-pipe machine locomotion is its warming. The coil of the electromagnet is excited by relatively high current $(1.6 \mathrm{~A})$ with regard to the diameter of the wire $(0.2 \mathrm{~mm})$ of the coil winding. Thus for long-term operation of the in-pipe machine it is necessary to optimize the time of the regeneration tact in which the coil of the in-pipe machine cools down. The warming of the electromagnet coil represents a dangerous risk of a coil winding damage. From that reason on the case of the coil the in-pipe machine is equipped with a "cooling radiator" by which the temperature exchanges the surface of the in-pipe machine is extended. The miniature temperature sensor Ni200 for the purpose of automatic adjustment of the regeneration tact time duration is implanted in the front part of the coil. The length of the path passed during one motion cycle is $0.32 \mathrm{~mm}$ under the simulation. The maximum steady velocity of the in-pipe machine is $4.8 \mathrm{~mm} / \mathrm{s}$ under the simulation (exciting frequency of $15 \mathrm{~Hz}$ ). Experimentally was reached the maximum in-pipe machine locomotion velocity of $5.55 \mathrm{~mm} / \mathrm{s}$. In respect of existing geometric deviations of the pipe inner surface the unstable operation of the in-pipe machine occurs in some places of the pipe.

The presented solution of mobile robot uses un-conventional type of locomotion. Many other types of robots use only wheeled locomotion which is sensitive to dirties and wheel slipping occurs. The proposed principle is better to smaller diameter pipes, where conventional locomotion types cannot be used.

\section{Acknowledgement}

This work was supported in part by the Grant Agency VEGA of the Slovak Ministry of Education Grant 1/0872/16 and $1 / 0389 / 18$. 


\section{References}

[1] AOSHIMA, S., TSUJIMURA, T., YABUTA, T.: A Miniature Mobile Robot Using Piezo Vibration for Mobility in a Thin Tube. Transactions of ASME, Journal of Dynamic Systems, Measurements and Control, 115, 270-278, 1993.

[2] IDOGAKI, T., KANAYAMA, H., OHYA, N., SUZUKI, H., HATTORI, T.: Characteristics of Piezoelectric Locomotive Mechanism for an In-Pipe Micro Inspection Machine. Proceedings of IEEE 6th International Symposium on Micro Machine and Human Science (MHS ‘95), Japan, 193-198, 1995.

[3] SUN, L., SUN, P., QIN, X., WANG, C.: Micro Robot in Small Pipe with Electromagnetic Actuator. Proceedings of the 1998 International Symposium on Micromechatronics and Human Science (MHS ‘98), Japan, 243-248, 1998.

[4] MATSUMOTO, T., OKAMOTO, H., ASANO, M., MITSUISHI, S., MATSUI, T.: A Prototype Model of Micro Mobile Machine with Piezoelectric Driving Force Actuator. Proceedings of IEEE 5th International Symposium on Micro Machine and Human Sciences (MHS '94), Japan, 47-54, 1994.

[5] FUKUDA, T., HOSOKAI, H., UEMURA, M.: Rubber Gas Actuator Driven by Hydrogen Storage Alloy for In-Pipe Inspection Mobile Robot with Flexible Structure. Proceedings of IEEE International Conference on Robotics and Automation, USA, 3, 1847 1852, 1989.

[6] IWASHITA, S., HAYASHI, I., IWATSUKI, N., NAKAMURA, K.: Development of in-pipe operation micro robots. Proceedings of IEEE 5th International Symposium on Micro Machine and Human Sciences (MHS ‘94), Japan, 41-45, 1994.

[7] SUZUMORI, K., MIYAGAWA, T., KIMURA, M., HASEGAWA, Y.: Micro Inspection Robot for 1-In Pipes. IEEE/ASME Transactions on Mechatronics, 4(3), 286-292, 1999.

[8] TAKAHASHI, M., HAYASHI, I., IWATSUKI, N., SUZUMORI, K., OHKI, N.: The Development of an In-Pipe Microrobot Applying the Motion of an Earthworm. Proceedings of IEEE 5th International Symposium on Micro Machine and Human Sciences (MHS ‘94), Japan, 35-40, 1994.

[9] SUN, L., SUN, P., QIN, X., WANG, C.: Micro Robot in Small Pipe with Electromagnetic Actuator. Proceedings of the 1998 International Symposium on Micromechatronics and Human Science (MHS '98), Japan, 243-248, 1998.

[10] HIROSE, S., OHNO, H., MITSUI, T., SUYAMA, K.: Design of In-Pipe Inspection Vehicles for -25, -50, -150 Pipes. Proceedings of IEEE International Conference on Robotics and Automation, USA, 2309-2314, 1999.

[11] DEGANI, A., FENG, S., CHOSET, H., MASON, M. T.: Minimalistic, Dynamic, Tube Climbing Robot. Proceedings of IEEE International Conference on Robotics and Automation, USA, 1100-1101, 2010.

[12] VITKO, A., JURISICA, L., KLUCIK, M., DUCHON, F.: Context Based Intelligent Behaviour of Mechatronic Systems. Acta Mechanica Slovaca, 12(3-B), 907-916, 2008.

[13] ANTAL, D.: Dynamical Modelling of a Path Controlled Vehicle. International Scientific Conference XXIV. micro CAD, Hungary, 1-6, 2010.

[14] GMITERKO, A., DOVICA, M., KELEMEN, M., FEDAK, V., MLYNKOVA, Z.: In-Pipe Bristled Micromachine. Proceedings of 7th International Workshop on Advances Motion Control, Slovenia, 467-472, 2002.

[15] GMITERKO, A., KELEMEN, M.: Bristled In-Pipe Micromachine Simulation. Mechatronika, 193-198, 2003.

[16] KELEMEN, M., MATASOVSKA, T.: Identification of the In-Pipe Machine Properties Based on Inertial Stepping Principle. AT\&P Journal, 13(1), 5, 2006.

[17] GMITERKO, A., KELEMEN, M., GOTS, I.: Basic Characteristics of In-Pipe Micromachine Karolina. Mechatronika, 146-151, 2001.

[18] KELEMEN, M., MATASOVSKA, T.: Simulation of the In-Pipe Machine Locomotion Based on the Innertial Stepping Principle. Bulletin of Applied Mechanics, 1(4), 231-246, 2005.

[19] KARAVAEV, Y. L., KILIN, A. A., KLEKOVKIN, A. V.: Experimental Investigations of the Controlled Motion of a Screwless Underwater Robot. Regular and Chaotic Dynamics, 21(7-8), 918-926, 2016.

[20] HARGAS, L., KONIAR, D., SIMONOVA, A., Hrianka, M., Loncova, Z.: Novel Machine Vision Tools Applied in Biomechatronic Tasks. Proceedings of 6th Conference on Modelling of Mechanical and Mechatronic Systems (MMaMS), Slovakia, 148-156, 2014. 